between policy makers and religious scholars. Dialogue on removing the discrepancies between risk awareness and actual knowledge in light with Quaran is likely to be more effective.

\section{P4.010 DETERMINING THE PATTERNS AND UPTAKE OF HIV TESTING AMONG YOUNG WOMEN IN TRINIDAD AND TOBAGO: IMPLICATIONS FOR HIV/AIDS POLICY}

doi:10.1136/sextrans-2013-051184.0909

B Andrews. Office of the Prime Minister, Port-of Spain, Trinidad and Tobago

Background In the Caribbean, young women are particularly at risk of being infected with HIV due to social, economic and behavioural vulnerabilities. However despite these vulnerabilties, few female young adults have been tested for HIVand know their status. Moreover there is a general paucity of studies examining the HIV testing behaviours, preferences and barriers faced among Caribbean youth. This study explores the patterns and factors associated with HIV testing behaviours among female youth aged 15-24 in three Caribbean countries: Guyana, Dominican Republic, and Haiti. The analysis is guided by Andersen's Behavioural Model.

Methods Data from population based surveys such as the Demographic and Health Surveys, the AIDS Indicator Survey are used to explore the determinants of HIV testing behaviour among young women. Independent variables were classified according to Andersen's Behavioural Model and includes: traditional predisposing variables (age, educational attainment, region of residence), vulnerable predisposing factors (age at first sex, recent sexual activity, lifetime partners, condom use, consistent condom use), predisposing variables (HIV knowledge, personal stigma attitudes, knowledge of persons living with HIV/AIDS) and enabling factors (socioeconomic status, exposure to print and non-print media, history of an STI). Statistical methods include bivariate analysis using chi-square and stepwise logistic regression modelling.

Results Proportion of youth ever tested was $17 \%$ in Haiti, $37 \%$ in Guyana and $48 \%$ in Dominican Republic. Factors associated with HIV testing were marital status, residence, age at first sex, socioeconomic status. Rural, poorer and unmarried young women were less likely to report that they were tested for HIV.

Conclusion Policies and programmes should address the structural, economic and other barriers to HIV testing faced by young women who reside in rural areas, and are poor. Messages promoting the benefits of HIV testing should target these women who are more vulnerable to HIV infection.

\section{P4.011 KNOWLEDGE OF HIV TRANSMISSION IN MALDIVIAN WOMEN: WHAT ARE ITS DETERMINANTS?}

doi:10.1136/sextrans-2013-051184.0910

${ }^{1} \mathbf{A}$ Thind, ${ }^{2} \mathrm{M}$ Aboobakur, ${ }^{2} \mathrm{~N}$ Rafiq, ${ }^{3} \mathrm{~A}$ Didi, ${ }^{1} \mathrm{M}$ Rab. 'University of Western Ontario, London, ON, Canada; ${ }^{2}$ Ministry of Health, Male, Maldives; ${ }^{3}$ UNDP, Male, Maldives

Maldives is a middle income country with a very low HIV prevalence. While the government has done a good job of raising awareness about AIDS in general, the level of appropriate HIV/AIDS related knowledge is low. The 2009 Demographic and Health Survey (DHS), which is a nationally representative survey of 7131 women, reported that while $97 \%$ of women had heard of AIDS, only $42 \%$ had a comprehensive knowledge about the disease. The level of HIV-related knowledge is a key factor in the spread of AIDS; we used the 2009 Maldives DHS to understand its determinants in women aged 15-49. Responses to questions assessing correct knowledge about modes of transmission (during pregnancy, delivery, breastfeeding, sexual intercourse, single partner, condom use, mosquito bites, and sharing food) were used to create a score, which was dichotomized by a median split to create a binary 'knowledge' (poor/good) variable. Poor/good knowledge was modelled as a function of socio-demographic (age, region, educational status, wealth, employment, and number of children), media (media exposure, internet use) and health/health system factors (use of family planning (FP), FP worker visit, health facility visit). On unadjusted analysis, older age, living in Male, being employed, number of children, media exposure, use of FP, and health facility visit were associated with having good knowledge of transmission modes. In the multivariate logistic regression, age $(\mathrm{OR}=1.04)$, higher educational level $(\mathrm{OR}=1.51)$, greater media exposure $(\mathrm{OR}=1.09)$, having a smaller number of children $(\mathrm{OR}=0.94)$, being employed $(\mathrm{OR}=1.12)$, FP use $(\mathrm{OR}=1.56)$ and health facility visit $(\mathrm{OR}=1.39)$ were statistically significant predictors of good knowledge of transmission modes. Our analysis indicates that while there are no regional or wealth related differences in level of knowledge about HIV transmission, the media and health facility visits can be used as vehicles to improve the knowledge level about HIV transmission in adult Maldivian women.

\section{P4.012 THE IMPACT OF STIGMA AND DISCRIMINATION IN MSM HIV-POSITIVE}

doi:10.1136/sextrans-2013-051184.0911

R Garcia, D G Ramos. Pontifical Catholic University of São Paulo; 05014-901, Brazil

Background Since its beginning, the Aids epidemic has established a series of social representations which impacted the daily life of men who have sex with men (MSM) living with HIV, who see themselves as doubly stigmatised due to their sexual orientation.

Methods The main objective of this study is observing the impact of stigma and discrimination in MSM living with HIV, while it specifically sets out an investigation on the possible implications HIV may bring to HIV-positive individuals as regards their perception of the disease, themselves as infected persons, their social circle and their sexual orientation, as well as the situations of vulnerability involved. The final objective is observing the different experiences of those infected before and after antiretrovirals (ARVs). This study is based on the theory of social representations, and the essentially qualitative-quantitative method used is the Discourse of the Collective Subject. The 33 participants, ranging from 20 to 60 years of age, were selected at a Centre for HIV/AIDS Treatment.

Results The results point to high rates of internalised stigma evidenced by feelings of fear, rejection, a constant state of alertness, and guilt. This perception was reflected in increased vulnerability, non-use of condoms and social isolation.

Conclusion The conclusion strongly recommends an investigation on the social, affective and sexual contexts where these individuals are inserted, while rethinking new ways of intervening in the prevention and treatment of people who live with HIV (PLWHIV).

\section{P4.013 PERCEPTIONS OF LIFE QUALITY OF PEOPLE WITH HIV/AIDS}

doi:10.1136/sextrans-2013-051184.0912

S Da Silva De Souza, B Horner Schlindwein Meirelles, D Maria Guerreiro Vieira Da Silva. Universidade Federal de Santa Catarina, Florianopolis, Brazil

A qualitative exploratory-descriptive objective "Identify the elements that influence the perception of quality of life (QOL) of people living with HIV/AIDS". Semi-structured interviews with 14 people have been carried out. The analysis resulted in four categories Quality of life: subjectivity and multidimensionality. Living with HIV/AIDS and the quality of life. Care for the living quality. Health services as enhancers of QOL. There are several factors that interfere on the QOL of those people such as: physical aspects caused by the disease, the continuation of the treatment and the 